\title{
Myofibroblast in Wound Contraction
}

\author{
R. S. Rakhi Menon
}

\begin{abstract}
Myofibroblasts differentiate and repair injured tissue by depositing the extracellular matrix in an organised manner and by contractile forces. When the repair is complete, there is scar formation and disappearance of myofibroblast by apoptosis.
\end{abstract}

Keywords: prosthetic

\section{Introduction}

Myofibroblast is a specialized contractile fibroblast that plays an important role in reconstruction of Connective tissue after injury and also in pathological tissue repair. Myofibroblast progenitor is locally residing fibroblast which differentiates into a proto myofibroblast. Differentiated myofibroblasts possess Extracellular Matrix (ECM) proteins and Alpha-Smooth Muscle Actin -negative stress fibres. ECF synthesis promotes tissue remodelling and the important fibroblast ECM products are Collagen Type I,III,IV and V Differentiation of fibroblast to Myofibroblast is a two step process : (1) to repopulate damaged tissues ,fibroblast acquire a migratory phenotype which consist of cytoplasmic actins that generate contraction forces (Boriz Hinz.,2001b). This phenotype changes occur due to changes in the composition and mechanical property of ECM (Hinz and Gabbiani, 2003b) and when the stress increases in the ECM due to Remodelling, proto-myofibroblast develops into 'Differentiated myofibroblast. Wound healing is characterized by myofibroblast and TGF-beta is the main stimulus for myofibroblast modulation (G.Gabbiani, Department of Pathology, Centre Medical Universitaire, Geneva, Switzerland)

\section{Myofiroblast Origin and Identification}

Fibroblast is originated from fibrocytes which is originally a group of bone marrow derived leukocytes (Abe et al., 2001). According to (Direkze et al., 2003; Mori et al., 2005) wound fibroblasts are derived from fibrocyte progenitors. It is identified by its Spindle or stellate shaped cell, pericellular matrix containing inter alia collagen and glycosaminoglycans, pale prominent eosinophilic cytoplasm.

It can also be derived from smooth muscle cells, pericytes, macrophages, specialised cells like hepatic stellate cells and epithelium. Ultimately from bone marrow via circulating blood borne fibrocytes (The myofibroblast in health and disease, Brain Edyen) .Immunophenotype - Vimentin positive, Alpha-smooth -muscle actin positive, non muscle myosin positive, reduced levels of desmin and smoothmuscle myosin, EDA cellular fibronectin positive

Ultra structure -prominent rough endoplasmic reticulum, Golgi apparatus producing collagen secretion granules, gap junctions and myofilaments (Brian Eyden)

\section{Cytoskeletal Markers}

Alpha Smooth muscle actin is the commonest marker used for the identification of myofibroblast. 4Ig isoform of the stress fibre protein paladin is also considered to be a marker especially for myofibroblast differentiation (Ronty et al., 2006, Boriz Hintz). But these markers indicates expression even in SMC, hence it can't be said the most reliable for distinguishing myofibroblast from SMC. Specific Cadherins like N- Cadherin (Cadherin -2) and A-CAM are surface markers which also are used to identify myofibroblast. It is recently been replaced by OB-Cadherin (Cadherin-11) but is absent from SMC, so cannot be considered as specific marker. The most reliable is the FN splice variant, marker of Myofibroblast ECM (Serini et al., 1998, B Hintz)

\section{Differentiation in Myofibroblast}

TGF Beta1 is promoting myofibroblast development by inducing expression of Alpha -SMA (Desmouliere et al., 1993; Ronnov-Jesen; B.Hinz and Petersen, 1993). The action of TGF Beta1 depends on the presence of Fibronectin splice variant ED-A and the differentiation is regulated by cellular products and components of extracellular matrix

\section{Wound Healing -Function of Myofibroblast}

Wound healing can be defined as the physiological process by which the body replaces and restores the function of damaged tissue. (Flanagan 1997). Initially after an injury ,resident stromal cells i.e. fibroblast is differentiated into myofibroblast and there is further switching on of nonmuscle actin in cells which consist of Rough endoplasmic reticulum ,stress fibres lacking Alpha-SMA and are spindle shaped .They are referred to as Protomyofibroblasts- earliest phase. Further development of myofibroblast is with the help of High levels of active Transforming growth factor (TGF-Beta), matrix molecules and a mechanically stressed environment. Platelet derived growth factor (PDGF) released from the blood in a wound will attract fibroblast (mitogen) and these will interact with PDGF-receptor bearing cells along with several cytokines. TGF-beta1 helps in development not only by inducing Alpha - Smooth Muscle expression but also by aiding in deposition of ECM like fibronectin and collagen. TGF -beta 1 action however is possible only in the presence of ED-A splice variant fibronectin (Micallef et al, fibro genesis and tissue repair 2012). Eventually there is precipitation and differentiation, ultimately myofibroblast is formed.

Role of Mechanical Stress - Mechanical tension is an important protocol which leads to formation of bundles of 


\section{International Journal of Science and Research (IJSR) \\ ISSN (Online): 2319-7064}

Index Copernicus Value (2015): 78.96 | Impact Factor (2015): 6.391

actin filaments known as stress fibres attached to membranes (Brandes et al)

\section{Role of Myofibroblast (Alpha-Sm Actin) In Wound Contraction \\ Alpha -SM actin i.e. differentiated myofibroblasts, produce a retractile activity that is stronger than the protomyofibroblasts in the absence of any change in the contractile protein expression (The evolution of the myofibroblast, G.Gabbiani). The SM cell contraction is Calcium dependent and reversible whereas the tension produced by the myofibroblast is irreversible and is regulated by Rho kinase mediated inhibition of myosin phosphatise. Alpha - SM actin expressing myofibroblast promotes contraction and also increases the levels of ECM components and matrix degradation proteases.}

\section{Normal and Pathological Wound Healing}

During healing there is restoration of the injured tissue with three dynamic phases known as an inflammatory phase, a proliferative phase and regeneration phase where there is scar formation and re - epithelialisation. During the remodelling phase proteolytic enzymes especially Matrix metalloproteinase's (MMPs) and Tissue Inhibitor of Metalloproteinase's (TIMP) plays a major role. Pathological wound healing occurs as a result of impaired remodelling, termed as fibrosis. When harmful stimulus persists there is excess of Extracellular matrix deposition which leads to internal organ fibrosis. To conclude there is imbalance in the myofibroblasts degradation and ECM synthesis (Micallef et al, From Fibro proliferative disorders, Frauenchiemsee, Germany 25-30 September 2010)

\section{Fate of Myofibroblast}

Myofibroblast along with the cells of neovasculature disappear by apoptosis after tissue repair (Gabbiani.G.The cellular derivation and the life span of the myofibroblast, $1996,192: 708-711)$. When apoptosis fails to occur, there is prolonged scarring leading to conditions like hypertrophic scar and keloid (The myofibroblast in health and disease, Brian Edyen)

\section{Conclusion}

It is important to understand normal wound healing mechanism and the role of myofibroblast in wound contraction to develop new therapeutic regimens for pathological tissue repair and other fibro proliferative disorders

\section{References}

[1] The evolution of the myofibroblast, G.Gabbiani, Department of Pathology, Centre Medical Universitaire, Geneva, Switzerland

[2] Micallef et al, From Fibro proliferative disorders, Frauenchiemsee, Germany 25-30 September 2010

[3] Gabbiani.G.The cellular derivation and the life span of the myofibroblast, 1996, 192:708-711.

[4] Micallef et al, fibro genesis and tissue repair 2012 The myofibroblast in health and disease, Brain Edyen
[5] Hinz B: Formation and function of the myofibroblast during tissue Repair. J Invest Dermatol 2007, 127:526 537

[6] Tomasek JJ, Gabbiani G, Hinz B, Chaponnier C, Brown RA: Myofibroblasts and mechano-regulation of connective tissue remodelling.

[7] Nat Rev Mol Cell Biol 2002, 3:349 -363

[8] Werner S, Grose R: Regulation of wound healing by growth factors and cytokines. Physiol Rev 2003, 83:835- 870

[9] Desmoulière A, Redard M, Darby I, and Gabbiani G. Apoptosis mediates the decrease in cellularity during the transition between granulation tissue and scar. Am J Pathol 1995; 146: 56-66.

[10]Hinz B, Darby IA, Gabbiani G, Desmoulière A: The role of the myofibroblast In fibrosis and cancer progression. In Tumour Associated Fibroblasts and Their Matrix. New York: Springer;Fusenig NE, Mueller MM 2011:37-74.

[11] Gurtner GC, Werner S, Barrandon Y, Longaker MT: Wound repair and Regeneration. Nature 2008, 453:314321.

[12] Serini G, Bochaton-Piallat ML, Ropraz P, Geinoz A, Borsi L, Zardi L, et al. The fibronectin domain ED-A is crucial for myofibroblastic phenotype induction by transforming growth factor-beta1. J Cell Biol 1998;142:873-81.

[13]Rønnov-Jessen L, Petersen OW, Koteliansky VE, Bissell MJ. The origin of the myofibroblasts in breast cancer.

[14] Recapitulation of tumour environment in culture unravels diversity and implicates converted fibroblasts and recruited smooth muscle cells. J Clin Invest 1995; 95: 859-873.

[15]Desmoulière A, Guyot C, Gabbiani G. The stroma reaction myofibroblast: a key player in the control of tumour cell behaviour. Int J Dev Biol 2004; 48: 509. 517.

[16] Bhawan J, Majno G. The Myofibroblast. Possible derivation from macrophages in xanthogranuloma. Am J Dermatopathol 1989; 11: 255-258.

[17] Bayes-Genis A, Campbell JH, Carlson PJ, Holmes DR, Schwartz RS. Macrophages, myofibroblasts and neointimal hyperplasia after coronary artery injury and repair. Atherosclerosis 2002; 163: 89-98

[18] Tian Y-C, Fraser D, Attisano L, Phillips AO. TGF- $\beta 1$ mediated alterations of renal proximal tubular epithelial cell phenotype. Am J Physiol Renal Physiol 2003; 285:F130-F142.

[19] Abe R, Donnelly SC, Peng T, Bucala R, Metz CN. Peripheral blood fibrocytes: differentiation pathway and migration to wound sites. J Immunol 2001; 166: 75567562.

[20] Schmidt TM, Sun G, Stacey MA, Mori L, Mattoli S. Identification of circulating fibrocytes as precursors of bronchial myofibroblasts in asthma. J Immunol 2003; 170: 380-389.

[21] Quan TE, Cowper C, Wu S-P, Bockenstedt LK, Bucala R. Circulating fibrocytes: collagen-secreting cells of the peripheral blood. Int J Biochem Cell Biol 2004; 36: 598-606. 


\section{International Journal of Science and Research (IJSR) \\ ISSN (Online): 2319-7064}

Index Copernicus Value (2015): 78.96 | Impact Factor (2015): 6.391

[22] Yamaguchi Y, Kubo T, Murakami T, Takahashi M, Hakamata Y, Kobayashi E, Yoshida S, Hosokawa K, Yoshikawa

[23] K, Itami S. Bone marrow cells differentiate into wound myofibroblasts and accelerate the healing of wounds with exposed bones when combined with an occlusive dressing. Br J Dermatol 2005; 152: 616-622.

[24] Jabs A, Moncada GA, Nichols CE, Waller EK, Wilcox JN. Peripheral blood mononuclear cells acquire myofibroblastic characteristics in granulation tissue. $\mathbf{J}$ Vasc Res 2005; 42: 174-180.

[25]Desmoulière A, Redard M, Darby I, and Gabbiani G. Apoptosis mediates the decrease in cellularity during the transition between granulation tissue and scar. Am J Pathol 1995; 146: 56-66. 